\title{
Homogeneity of Continuum Model of an Unsteady State Fixed Bed Reactor for Lean $\mathrm{CH}_{4}$ Oxidation
}

\author{
Subagjo $^{1}$, Yogi Wibisono Budhi ${ }^{1 *}$, M. Effendy ${ }^{1} \&$ Yazid Bindar $^{2}$ \\ ${ }^{1}$ Research Group of Chemical Engineering Process Design and Development \\ Faculty of Industrial Technology, Institut Teknologi Bandung \\ Jalan Ganesha 10, Bandung 40132, Indonesia \\ ${ }^{2}$ Research Group of Chemical Engineering Energy and Processing System \\ Faculty of Industrial Technology, Institut Teknologi Bandung \\ Jalan Ganesha 10, Bandung 40132, Indonesia \\ *Email: Y.Wibisono@che.itb.ac.id
}

\begin{abstract}
In this study, the homogeneity of the continuum model of a fixed bed reactor operated in steady state and unsteady state systems for lean $\mathrm{CH}_{4}$ oxidation is investigated. The steady-state fixed bed reactor system was operated under once-through direction, while the unsteady-state fixed bed reactor system was operated under flow reversal. The governing equations consisting of mass and energy balances were solved using the FlexPDE software package, version 6. The model selection is indispensable for an effective calculation since the simulation of a reverse flow reactor is time-consuming. The homogeneous and heterogeneous models for steady state operation gave similar conversions and temperature profiles, with a deviation of 0.12 to $0.14 \%$. For reverse flow operation, the deviations of the continuum models of thepseudo-homogeneous and heterogeneous models were in the range of $25-65 \%$. It is suggested that pseudo-homogeneous models can be applied to steady state systems, whereas heterogeneous models have to be applied to unsteady state systems.
\end{abstract}

Keywords: continuum model; mathematical modeling; methane; oxidation; reverse flow reactor; simulation.

\section{Introduction}

The classification of continuum models given by Froment and Bischoff has been widely applied in chemical engineering [1]. Froment and Bischoff have classified the continuum models into two groups, namely pseudo-homogeneous and heterogeneous models. This classification is based on the transport processes between gas phase and solid phase. One of the applications for fixed bed reactors is the reverse flow reactor (RFR). In the last decade, the reverse flow reactor has received a great deal of attention due to its involvement of the process of heat integration, which offers benefits in the technical and economic aspects. The RFR has been widely used to treat waste gases containing volatile organic compounds (VOC), emitted from stacks, greenhouse gases from coal mine ventilation, or lean methane leaked from compressor stations in the oil and

Received June $8^{\text {th }}, 2013$, Revised March 21 ${ }^{\text {st }}, 2014$, Accepted for publication April 30 ${ }^{\text {th }}, 2014$.

Copyright () 2014 Published by ITB Journal Publisher, ISSN: 2337-5779, DOI: 10.5614/j.eng.technol.sci.2014.46.2.6 
gas industry [2]. The RFR has proven efficient for treating lean and fluctuated feed gas concentrations due to its capability to operate under autothermal conditions.

Studies of the RFR have been conducted through modeling and simulation as well as in laboratory experiments. Both ways are important for observing the dynamic behavior of the RFR. Various mathematical models have been proposed to predict the dynamic behavior of the RFR, from simple models (pseudo-homogeneous one-dimensional models) [3,4] to complex models (heterogeneous one-dimensional models) $[5,6]$.

In an RFR, the model complexity is often higher when compared to a fixed bed reactor, once-through operation as a result of the involvement of mass and energy accumulations in the mathematical model, caused by periodically reversing the flow direction. This affects the boundary conditions in the model $[7,8]$. The accumulations of heat and mass occurring in the RFR influence the rate of heat and mass transfer from the bulk gas to the solid surface or from the solid surface to the bulk gas. These effects determine the appropriateness of the continuum model selection (pseudo-homogeneous model or heterogeneous model) [9]. The selected model is critical when working on the dynamic operation of a system such as the RFR since the boundary conditions may alter periodically over time.

Mears' criterion is frequently applied for the selection of the continuum model. For example, Salinger and Eigenberger [10] used the pseudo-homogeneous model under steady state conditions when the chemical reaction was controlled by kinetics rather than mass transfer. The temperature of the gas and solid phases were very similar, to the extent that their differences could be neglected. Iordanidis [11] showed the differences between the homogeneous and the heterogeneous models based on the deviation limits according to the idea of Mears. The results obtained showed that there was no significant difference between the pseudo-homogeneous and the heterogeneous models for ethylene oxidation operated under steady state conditions.

Study of the continuum model for selecting a pseudo-homogeneous or a heterogeneous model is usually conducted under steady state conditions. Very little attention has been paid to the case of unsteady state conditions, whereas in fact many applications in the chemical processes take place under unsteady state conditions. Therefore, the purpose of this study was to identify the homogeneity of the continuum model for methane oxidation in a fixed bed reactor system operating under unsteady state conditions. In this study, the unsteady state operation was intentionally created by reversing the flow direction. 


\section{Mathematical Model in Reverse Flow Reactor}

According to Hevia, et al. [12], the one-dimensional model is sometimes accurate enough to describe the behavior of a reverse flow reactor at the laboratory scale. The radial profiles of temperature and concentration may be neglected because of the relatively small diameter of the reactor when compared to its length (very small radial Biot number). The pressure drop along the reactor may also be neglected. An ideal gas behavior for the gas phase was assumed. The continuum model of the fixed bed reactor for unsteady state conditions was developed based on a one-dimensional (1-D) model with axial dispersions. The latter term was intentionally included with the aim to stabilize the numerical calculation. The dispersion number was checked and it remained lower than $10^{-3}[13]$.

The governing equations for the RFR are in principle the same as steady state equations, but the accumulation terms that describe the rate of changes of temperature and concentration over time $(\partial T / \partial t$ and $\partial C / \partial t)$ are important to be included. Reversing the flow direction is invoked by changing the velocity sign $u_{z}(t)=u_{z} * k(t)$, where $k(t)$ is +1 or -1 depending on flow direction. The mass and energy balances of the fixed bed reactor heterogeneous model are as follows:

Mass balance for the gas phase:

$$
\frac{\partial C_{C H_{4, g}}}{\partial t}=D_{e f f} \frac{\partial^{2} C_{C H_{4, g}}}{\partial z^{2}}-u_{z}(t) \frac{\partial C_{C H_{4, g}}}{\partial z}+k_{f} a_{v}\left(C_{C H_{4, s}}-C_{C H_{4, g}}\right)
$$

Energy balance for the gas phase:

$$
\left(\varepsilon_{b} C_{p, g} \rho_{g}\right) \frac{\partial T_{g}}{\partial t}=-u_{z}(t) C_{p, g} \rho_{g}^{o} \frac{\partial T_{g}}{\partial z}-h_{s} a_{v}\left(T_{g}-T_{s}\right)-\frac{4 U_{w}}{d_{t}}\left(T_{g}-T_{a}\right)
$$

Mass balance for the solid phase:

$$
\begin{aligned}
& k_{f} a_{v}\left(C_{C H_{4, s}}-C_{C H_{4, g}}\right)=-r_{C_{4}}, \text { for the catalytic bed } \\
& k_{f} a_{v}\left(C_{C H_{4, s}}-C_{C H_{4, g}}\right)=0 \text {, for the inert bed }
\end{aligned}
$$

Energy balance for the solid phase:

$$
\left(\varepsilon_{b} C_{p, g} \rho_{g}+\left(1-\varepsilon_{b}\right) C_{p, s} \rho_{s}\right) \frac{\partial T_{s}}{\partial t}=k_{e f f} \frac{\partial^{2} T_{s}}{\partial z^{2}}+h_{s} a_{v}\left(T_{g}-T_{s}\right)+\Delta H_{r} r_{C H_{4}}
$$

Concerning the boundary conditions, Danckwert's boundary condition was used for the simulation of the unsteady catalytic reactor following Marin, et al. [14]. 
Inlet:

$$
\begin{aligned}
& u_{z} C_{C H_{4}, g}^{o}=u_{z} C_{C H_{4}, g}-D_{e z} \frac{d C_{C H_{4}}}{d z} \\
& \rho_{g}^{o} u_{z} C_{p, g} T_{g}^{o}=\rho_{g} u_{z} C_{p, g} T_{g}-\lambda_{e z} \frac{d T_{g}}{d z} \\
& \frac{d T_{s}}{d z}=0
\end{aligned}
$$

Outlet:

$$
\begin{aligned}
& \frac{d T_{g}}{d z}=0 \\
& \frac{d T_{s}}{d z}=0 \\
& \frac{d C_{C H_{4, g}}}{d z}=0
\end{aligned}
$$

The mass balance for the gas phase (Eq. (1)) included the gas convection, the axial diffusion due to non-ideal gas flow, and the mass transport between the gas and solid phases. The same pattern was followed by the energy balance to the gas phase (Eq. (2)) and any extra heat for taking into account the energy transport between the gas phase and surroundings. In the mass balance for the solid phase (Eqs. (3) and (4)), the transient term was neglected, assuming a pseudo-steady state condition [12].

While the one-dimensional pseudo-homogeneous model with dispersion in unsteady conditions was obtained by assuming that the temperature and gas concentration in the bulk phase were the same as for the catalyst surface, so that: $T_{s}=T_{g}$ and $C_{C H 4, s}=C_{C H 4, g}$. The mass and energy balances of the pseudohomogeneous model of the fixed bed reactor are as follows, together with the boundary conditions:

Mass balance:

$$
\frac{\partial C_{C H_{4}}}{\partial t}=D_{e f f} \frac{\partial^{2} C_{C H_{4}}}{\partial z^{2}}-u_{z}(t) \frac{\partial C_{C H_{4}}}{\partial z}-r_{C H_{4}}
$$


Energy balance:

$$
\begin{aligned}
\left(\varepsilon_{b} C_{p, g} \rho_{g}+\left(1-\varepsilon_{b}\right) C_{p, s} \rho_{s}\right) \frac{\partial T}{\partial t}= & -u_{z}(t) C_{p, g} \rho_{g} \frac{\partial T}{\partial z}+k_{e f} \frac{\partial^{2} T}{\partial z^{2}}+\Delta H_{r} r_{C H_{4}} \\
& -\frac{4 U_{w}}{d_{t}}\left(T-T_{a}\right)
\end{aligned}
$$

Danckwert's boundary condition:

Inlet:

$$
\begin{aligned}
& \rho_{g}^{o} C_{p} u_{z} T^{o}=\rho_{g} C_{p} u_{z} T-\lambda_{e z} \frac{d T}{d z} \\
& u_{z} C_{C H_{4}}^{o}=u_{z} C_{C H_{4}}-D_{e z} \frac{d C_{C H_{4}}}{d z}
\end{aligned}
$$

Outlet:

$$
\begin{aligned}
& \frac{d T}{d z}=0 \\
& \frac{d C_{C H_{4}}}{d z}=0
\end{aligned}
$$

The initial conditions of the mass and energy balances of the unsteady state operation, either in the pseudo-homogeneous or the heterogeneous model,used the results of the steady state operation.

The models were solved using the finite element method (FEM), based on approximation of the spatial derivatives by finite element. The resulting system of partial differential equations was solved using the software package FlexPDE, version 6, which is particulary recommended for stiff problems.

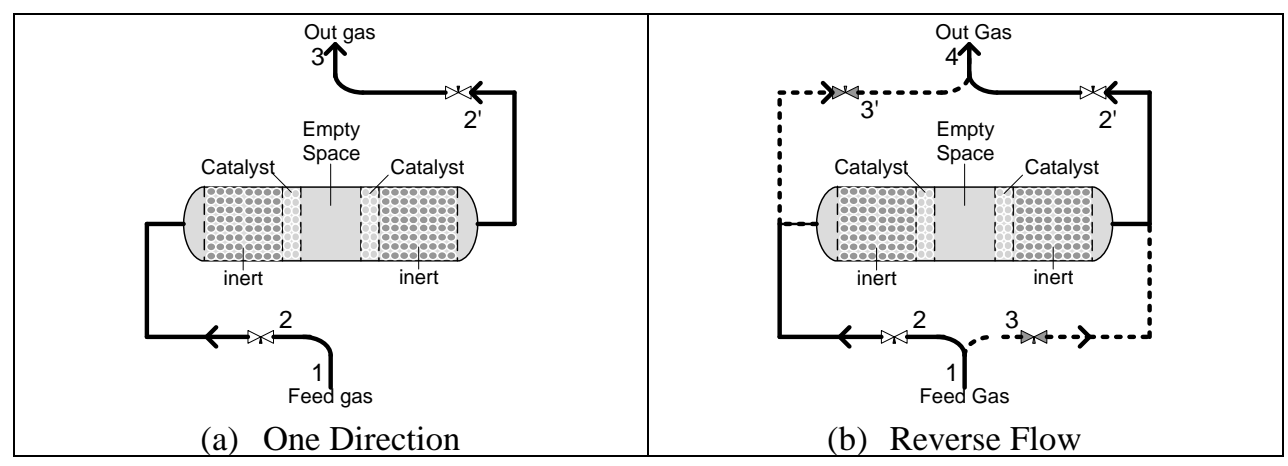

Figure 1 Configuration of fixed bed reactor. 
The fixed bed reactor configuration used in this model consisted of five zones, namely: left side inert zone, left side of the catalyst, heat extractor, right side of the catalyst, and right side inert zone. Figure 1 shows the configuration of the fixed bed reactor operated in once-through direction and reverse flow direction. Main operating conditions, kinetic parameters, and physical properties used in the simulation study are shown in Table 1. In the design criterion, the effectiveness factor was calculated to have a value of 0.95 .

Table 1 Main operating conditions, kinetic parameter, and physical properties used in this study.

\begin{tabular}{|c|c|c|}
\hline Dimensionless reactor & $\begin{array}{l}\mathrm{L}_{\text {inert }}(\mathrm{m}) \\
\mathrm{L}_{\text {catalyst }}(\mathrm{m}) \\
\mathrm{L}_{\text {heat exchanger }}(\mathrm{m}) \\
\mathrm{d}_{\text {tube-in }}(\mathrm{m}) \\
\mathrm{t}_{\mathrm{sS}}(\mathrm{m})\end{array}$ & $\begin{array}{c}2 \times 0.1 \\
2 \times 0.02 \\
0.04 \\
0.0147 \\
0.0032 \\
\end{array}$ \\
\hline Material properties for inert, $\mathrm{Al}_{2} \mathrm{O}_{3}[15]$ & $\begin{array}{l}\rho_{\text {inert }}\left(\mathrm{kg} / \mathrm{m}^{3}\right) \\
C \mathrm{p}_{\text {inert }}(\mathrm{J} / \mathrm{kg} \cdot \mathrm{K}) \\
\mathrm{k}_{\text {inert }}(\mathrm{W} / \mathrm{m} \cdot \mathrm{K}) \\
\varepsilon_{\text {bed }}(-) \\
\mathrm{d}_{\text {ball }}(\mathrm{m})\end{array}$ & $\begin{array}{c}1440 \\
1040 \\
1.46 \\
0.4 \\
0.003\end{array}$ \\
\hline Material properties for reactor [15] & $\begin{array}{l}\rho_{\mathrm{ss}}\left(\mathrm{kg} / \mathrm{m}^{3}\right) \\
\mathrm{Cp}_{\mathrm{ss}}(\mathrm{J} / \mathrm{kg} \cdot \mathrm{K}) \\
\mathrm{K}_{\mathrm{ss}}(\mathrm{W} / \mathrm{m} \cdot \mathrm{K})\end{array}$ & $\begin{array}{l}7800 \\
460 \\
14.3\end{array}$ \\
\hline $\begin{array}{l}\text { Material properties for catalyst, } 0.5 \% \\
\mathrm{Pt} / \mathrm{Al}_{2} \mathrm{O}_{3}[14]\end{array}$ & $\begin{array}{l}\rho_{\text {bed inner }}\left(\mathrm{kg} / \mathrm{m}^{3}\right) \\
\mathrm{Cp}_{\text {catalyst }}(\mathrm{J} / \mathrm{kg} \cdot \mathrm{K}) \\
\mathrm{k}_{\text {catalyst }}(\mathrm{W} / \mathrm{m} \cdot \mathrm{K}) \\
\varepsilon_{\text {bed inner }}(-) \\
\mathrm{d}_{\text {catalyst }}(\mathrm{m}) \\
\tau(\mathrm{s}) \\
\varepsilon_{\text {catalyst }}(-)\end{array}$ & $\begin{array}{c}1082 \\
836 \\
0.042 \\
0.36 \\
0.0002 \\
2 \\
0.519\end{array}$ \\
\hline Material properties for isolator [15] & $\begin{array}{l}\rho_{\text {isolator }}\left(\mathrm{kg} / \mathrm{m}^{3}\right) \\
\mathrm{Cp}_{\text {isolator }}(\mathrm{J} / \mathrm{kg} \cdot \mathrm{K}) \\
\mathrm{k}_{\text {isolator }}(\mathrm{W} / \mathrm{m} \cdot \mathrm{K}) \\
\mathrm{t}_{\text {isolator }}(\mathrm{m}) \\
\end{array}$ & $\begin{array}{c}128 \\
1340 \\
0.144 \\
0.28 \\
\end{array}$ \\
\hline $\begin{array}{l}\text { Operating conditions and kinetic } \\
\text { parameters [16] }\end{array}$ & $\begin{array}{l}\mathrm{E}_{\mathrm{a}}(\mathrm{J} / \mathrm{mol}) \\
\mathrm{k}(1 / \mathrm{s}) \\
\mathrm{u}_{\mathrm{z}}(\mathrm{m} / \mathrm{s}) \\
\mathrm{C}^{\mathrm{o}}{ }_{\mathrm{CH} 4}\left(\mathrm{~mol} / \mathrm{m}^{3}\right) \\
\rho_{\text {gas }}\left(\mathrm{kg} / \mathrm{m}^{3}\right) \\
\mathrm{Cp}_{\text {gas }}(\mathrm{J} / \mathrm{kg} \cdot \mathrm{K}) \\
\mathrm{k}_{\text {gas }}(\mathrm{W} / \mathrm{m} \cdot \mathrm{K}) \\
\mu_{\text {gas }}(\mathrm{kg} / \mathrm{m} \cdot \mathrm{s}) \\
\end{array}$ & $\begin{array}{c}98324 \\
2.24 \times 10^{7} \\
0.7 \\
0.40 \\
0.45 \\
1122.92 \\
0.0554 \\
3.82 \times 10^{-5} \\
\end{array}$ \\
\hline
\end{tabular}




\section{Results and Discussion}

\subsection{Steady State Operation}

The first part of the study was the simulation of a catalytic packed-bed reactor that operates under steady state conditions. Figure 2 shows the effects of the

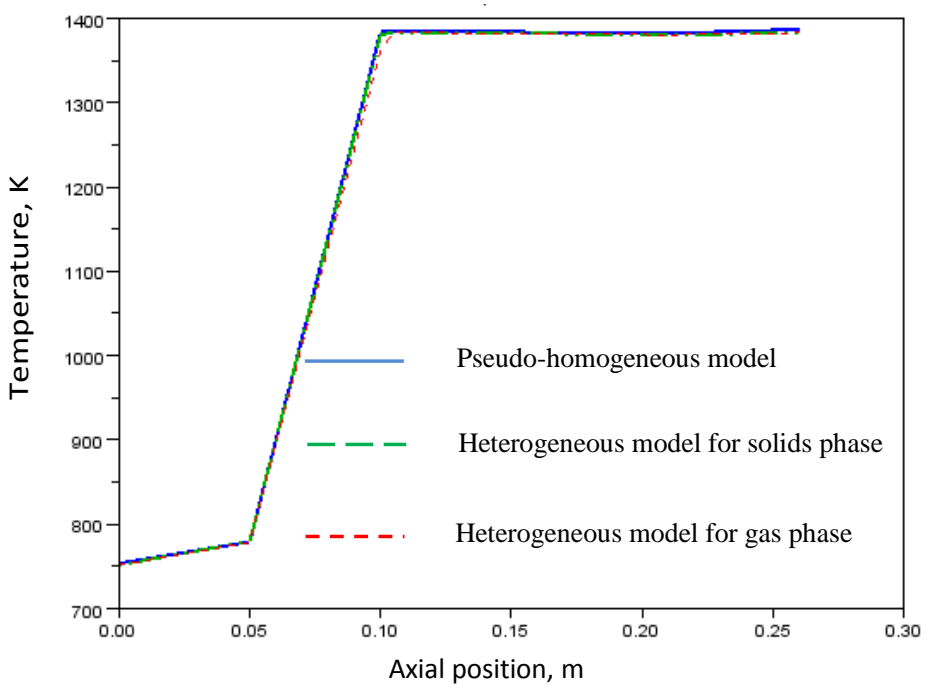

(b) Temperature profile at all positions in the reactor.

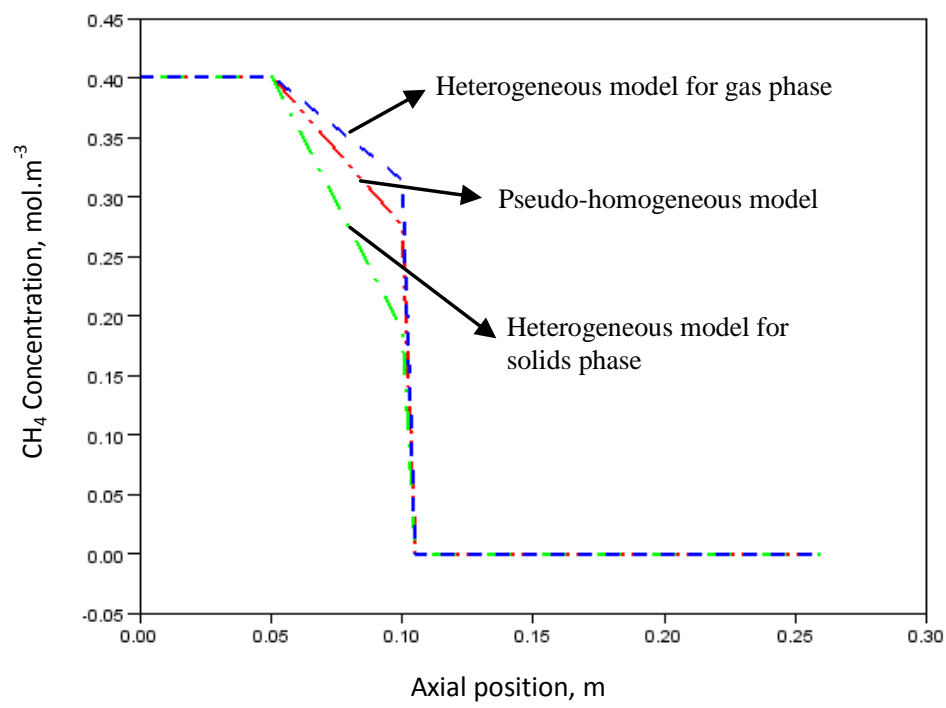

(a) Methane concentration profile at all positions in the reactor.

Figure 2 Comparison of pseudo-homogeneous and heterogeneous continuum models: (a) temperature profile and (b) methane concentration profile. 
differences between the pseudo-homogeneous and heterogeneous models at steady state. The feed gas entered the reactor from the left part (inlet) at a temperature of $750 \mathrm{~K}$ with a concentration of $0.4 \mathrm{~mol} / \mathrm{m}^{3}$. The reaction occurred in the catalyst zone that was located at position 0.1 to $0.11 \mathrm{~m}$ from the left end (see Figure 2(b)). It is indicated that the temperature profiles in the case of using the pseudo-homogeneous and heterogeneous models coincided along the reactor bed, whereas the concentration profiles showed different values when the feed gas was near the catalyst zone, just before entering the reaction section. The maximum temperatures in the catalyst section for both models were similar, i.e. around $1380 \mathrm{~K}$. In the outlet section, where the heat brought by the effluent is removed into the environment, the temperature profiles looked horizontal.

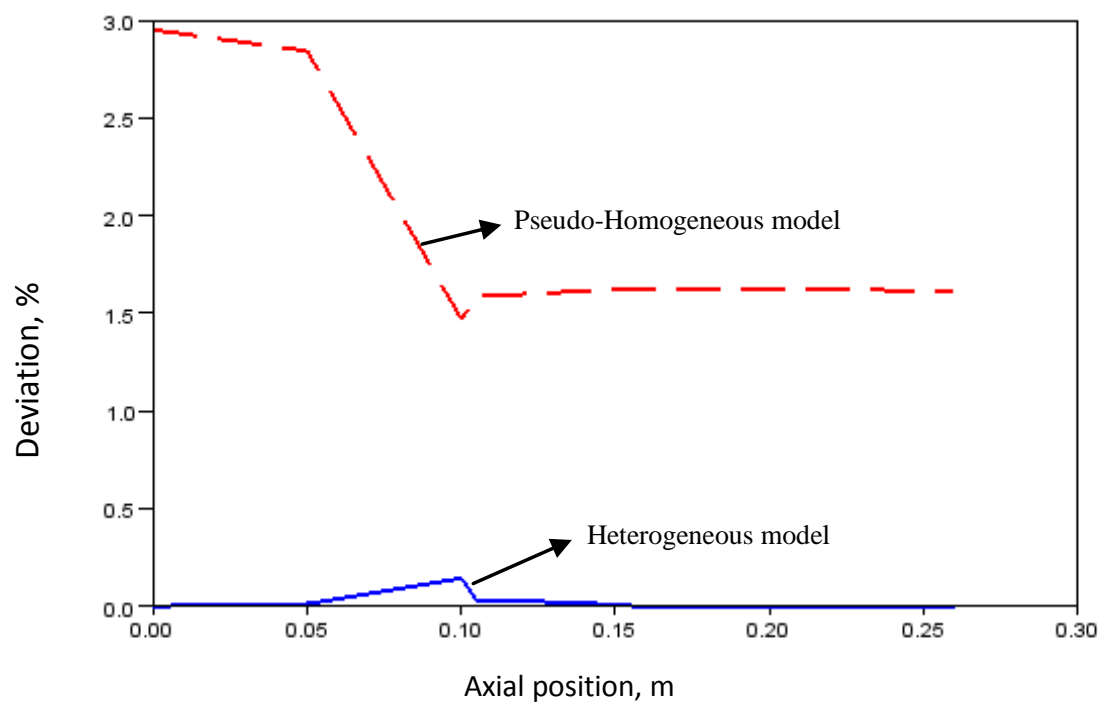

Figure 3 Temperature deviation of pseudo-homogeneous model and heterogeneous model under steady state operation.

Figure 3 shows that the deviation values for both models are less than $3 \%$. Although the deviation value of the heterogeneous model is much lower compared to that of the pseudo-homogeneous model, the difference is not too large and can be neglected. Therefore it can be concluded that the pseudohomogeneous and heterogeneous models can be applied for catalytic oxidation of methane to produce $\mathrm{CO}_{2}$. This means that the pseudo-homogeneous model is accurate enough for describing the phenomena that occur in a fixed bed reactor for catalytic oxidation of methane under steady state conditions. 


\subsection{Unsteady State Operation}

The second part of the study was the simulation of a catalytic packed-bed reactor operated under unsteady state conditions. This condition was maintained by periodically changing the direction of flow. During start-up, the reactor section was preheated (using an external heat source) to $500^{\circ} \mathrm{C}$ (ignition temperature). Control valves 2 and 2' were open (while valves 3 and 3' were closed) for forward flow; control valves 3 and 3' were open (while valves 2 and 2' were closed) for reverse flow (Figure 1(b)). Both in forward flow and reverse flow, the heat of the reaction was stored in the inert section, located at the exit flow. This stored heat was then used to preheat the feed gas when the flow direction was reversed. Figure 4 shows the temperature profile along the reactor when the flow direction was to the left and right when the temperature reached a stable oscillation. The temperature profile as a function of time is presented in Figure 5.

When the flow direction is from left to the right (see solid line in Figure 4), the heat released by the exothermic reaction will be stored in the inert material in the downstream section by two mechanisms, i.e. heat conduction and heat convection. The heat will be stored in the inert material, which can be used for heating the feed gas for the subsequent flow from the opposite direction. When the switching time is very long, the heat accumulation becomes large, which increases the temperature of the inert material. As can be seen in Figure 4, the reactor temperature in the inert section is larger than that of the centre one. When the feed gas is reversed with the feed gas at ambient temperature ( $303 \mathrm{~K})$, the heat stored in the inert material section will be transferred for heating up the feed gas before entering the reaction section. The process of transferring heat from the solid inert material into the feed gas will take place as long as the heat stored in the inert material is available. This is to ensure that the feed gas will reach the reaction temperature when the gas enters the catalyst section. As the stored heat is continuously withdrawn, the temperature of the inert material decreases as a function of time. The flow direction from right to left has to be reversed before the reaction section is extinguished.

The dynamic behavior of the reverse flow reactor indicates that the temperature of the solid (inert and catalyst) will always alter over time. The maximum temperature that can be achieved when using the heterogeneous model is equal to $1300 \mathrm{~K}$, while using the pseudo-homogeneous model it is $1850 \mathrm{~K}$. In the heterogeneous model, the heat transfer will occur from solid to gas (catalyst and inert zone during heat saving) or otherwise from gas to solid (inert zone). In the pseudo-homogeneous model, the heat transfer between gas phase and solid phase will not occur. Since there is a heat transfer limitation in the heterogeneous model, the maximum temperature in the catalyst is much lower 
than that of the pseudo-homogeneous model. When compared to the steady state operation, the temperature achieved for the heterogeneous model is lower. This

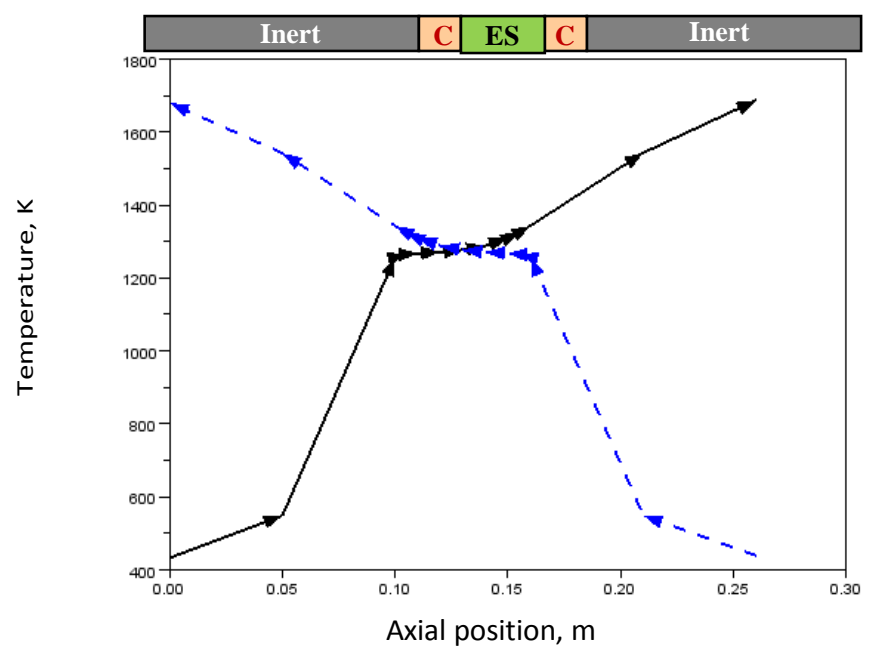

(a) Pseudo-Homogeneous model

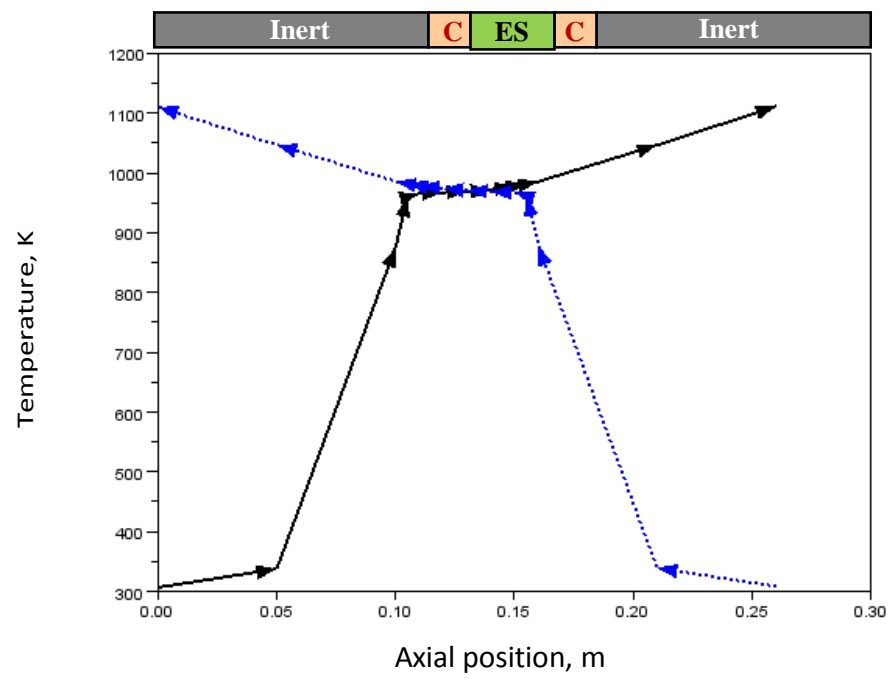

(b) Heterogeneous model

Figure 4 Temperature profile along the reactor bed: (a) the pseudohomogeneous model and (b) the heterogeneous model taken just before the flow direction is reversed when the temperature has reached a stable oscillation. $\mathrm{C}=$ catalyst; ES = empty space. Switching time was set at $300 \mathrm{~s}$. 
means that during reverse flow operation, even stable oscillation of the process has been gained, but the temperature in the catalyst section still propagates during the cycle. At this switching time, it seems that part of the heat released by the exothermic reaction will dissipate into the environment. Due to the heat transfer limitation involved in the heterogeneous model, the heat movement from the catalyst to the environment will face many resistances.

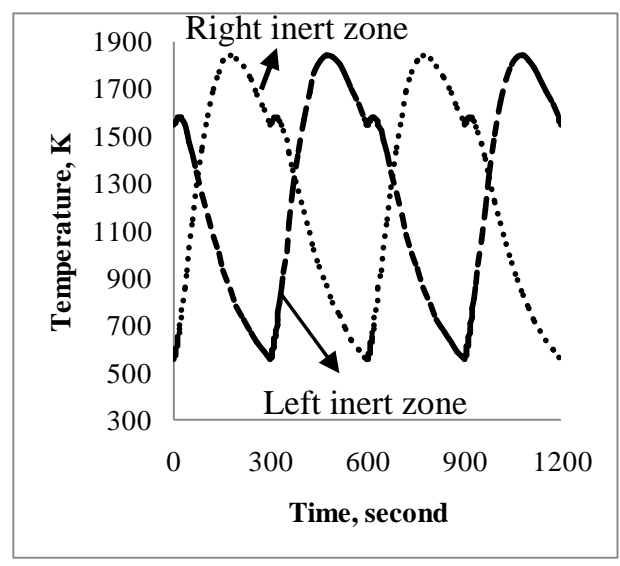

(a) Pseudo-Homogeneous Model

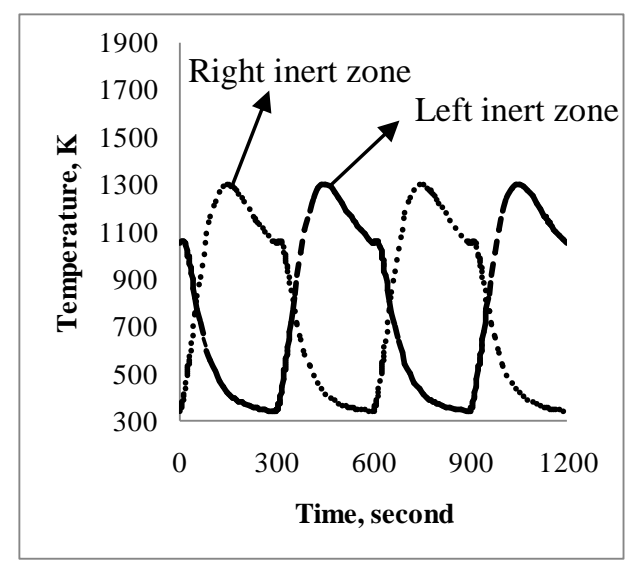

(b) Heterogeneous Model

Figure 5 Temperature profile at any time: (a) pseudo-homogeneous model and (b) heterogeneous model taken in the middle of an inert when the temperature has reached a stable oscillation with time reversal every 300 seconds.

The dynamic temperature change as a function of time in the middle part of the inert zone is presented in Figure 5 for both models. From this figure, it is obvious that the temperature of the inert material at a fixed point will always alter due to the propagation of the heat flow by conduction and convection. The temperature increase as shown in each cycle is induced by heat storage in which the hot effluent gas transfers its energy to the inert material. On the other hand, the temperature decrease as shown in each cycle is induced by heat extraction in which the cold feed gas takes the heat from the inert material. The temperature profile for the pseudo-homogeneous model also indicates that the temperature in the centre part of the inert material decreases stiffly and subsequently increases after the flow direction is changed. There is no indication that the temperature will reach the steady state conditon. On the other hand, the heterogeneous model indicates that after reaching low temperature, steady state conditions seem to be achieved. 
In Figure 5, it can be clearly observed that the inert material used in the reverse flow reactor can act as heat storage. The inert material will store the heat from the hot gas and it will release the heat to the cold feed gas. The direct contact between gas phase and solid phase will induce a better efficiency during heat transfer. The energy efficiency can reach up to $95 \%$, which is much better than in a conventional reactor [17].

The use of the continuum model for pseudo-homogeneous and heterogeneous models in reverse flow operation gives a similar trend of temperature profile characteristics, but the values are significantly different (see Figure 5). In the pseudo-homogeneous model, the maximum temperature at the center part of the inert material is $1850 \mathrm{~K}$, whereas in the heterogeneous model the maximum temperature is $1300 \mathrm{~K}$. The temperature deviation, which occurs at each point of observation, was taken after reaching a stable oscillation. Figure 6 shows the deviation of the models used in the reverse flow reactor simulation for methane oxidation. The comparison of the model types was used to investigate the differences of the temperature profile during reactor operation, particularly regarding the dynamic processes.

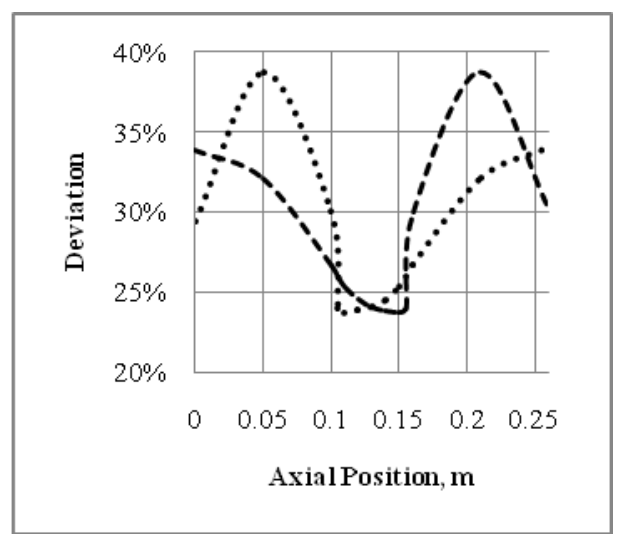

(a) Deviation profile calculated by comparing temperature $T$ simulated under pseudo-homogeneous models of mass and energy and solid temperature $T_{s}$ simulated under a pseudo-homogeneous model of mass, but heterogeneous model of heat.

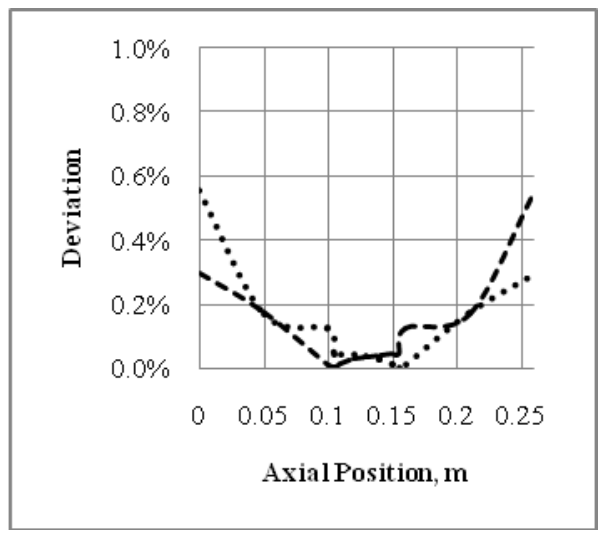

(b) Deviation profile calculated by comparing temperature $T$ simulated under pseudo-homogeneous models of mass and energy and solid temperature $T_{s}$ simulated under a pseudo-homogeneous model of heat and a heterogeneous model of mass.

Figure 6 Deviation of temperature profile. $(\ldots \ldots \ldots)=$ flow from left to right, and $\left(--_{--)}=\right.$flow from right to left, when the temperature has reached a stable oscillation with $t_{s}=300 \mathrm{~s}$.

The deviation values of the pseudo-homogeneous and the heterogeneous models change as a function of time. This phenomenon is induced by the propagation of the temperature profile in each section of the reactor bed, as shown in Figure 5. When the temperature profile has reached a stable oscillation, the temperature 
deviation profile for the direction of gas flow to the left will be like a mirror image of the deviation profile for the gas flow to the right (see Figure 6) at similar time after reversing the flow direction. The temperature deviation profiles will always follow the characteristic of the temperature profile under dynamic reactor operation.

According to Figure 6, the deviation from the pseudo-homogeneous and heterogeneous models of mass and heat from the model with a pseudohomogeneous model of heat and a heterogeneous model of mass was always over 23\%. This indicates that application of pseudo-homogeneous models of mass and heat will deviate significantly from a heterogeneous model of heat (Figure 6(a)), while pseudo-homogeneous models of mass and heat will not deviate significantly from a homogeneous model. This also implies that the application of homogeneous models of mass and heat is not suitable under dynamic reactor operation. It has been proven that this was less critical when the simulation was conducted under steady state operation, but this was not the case during transient operation. Therefore, it is strongly recommended to implement the heterogeneous model of the heat balance during dynamic operation. The influence of the heterogeneous model of mass is not too significant, and it is acceptable when using the pseudo-homogeneous model for mass during dynamic operation.

\section{Conclusions}

The development of a preliminary model for pseudo-homogeneous and heterogeneous models both for mass and heat balances has allowed us to identify some fundamental principles for choosing the appropriate modeling and simulation with particular attention to the deviation between the pseudohomogeneous model and the heterogeneous model. The chosen application of lean methane oxidation was taken into account, since it has been widely considered by many research groups concerning the most important issue of greenhouse gas emission. The developed model consists of mass and energy balances both in the gas phase and solid phase. The initial value and boundary condition value of Danckwert were implemented. It was shown that the pseudohomogeneous model resulted in a temperature profile similar to the temperature profile of the heterogeneous model when operated under steady state (one flow direction). The pseudo-homogeneous and the heterogeneous models resulted in a similar temperature profile when operated under steady state (one flow direction). On the other hand, in unsteady state operation of the fixed bed reactor, the deviation between the pseudo-homogeneous model and the heterogeneous model of the heat balance ranged from 23-38\%, while it was only a few percent for the mass balance. The influence of the mass balance was less profound when compared to the heat balance. Since the simulation of the 
reverse flow reactor involved the dynamic boundary condition at every switching time, the computation time becomes a crucial issue. Therefore, for the simplicity of the simulation, the mass balance can be conducted under pseudohomogeneous models, while this is not the case for the energy balance.

\section{Acknowledgments}

The financial support provided by "Research and Innovation ITB 2012" with contract number 188/I1.C06/PL/2012 is gratefully acknowledged.

\section{Nomenclature}

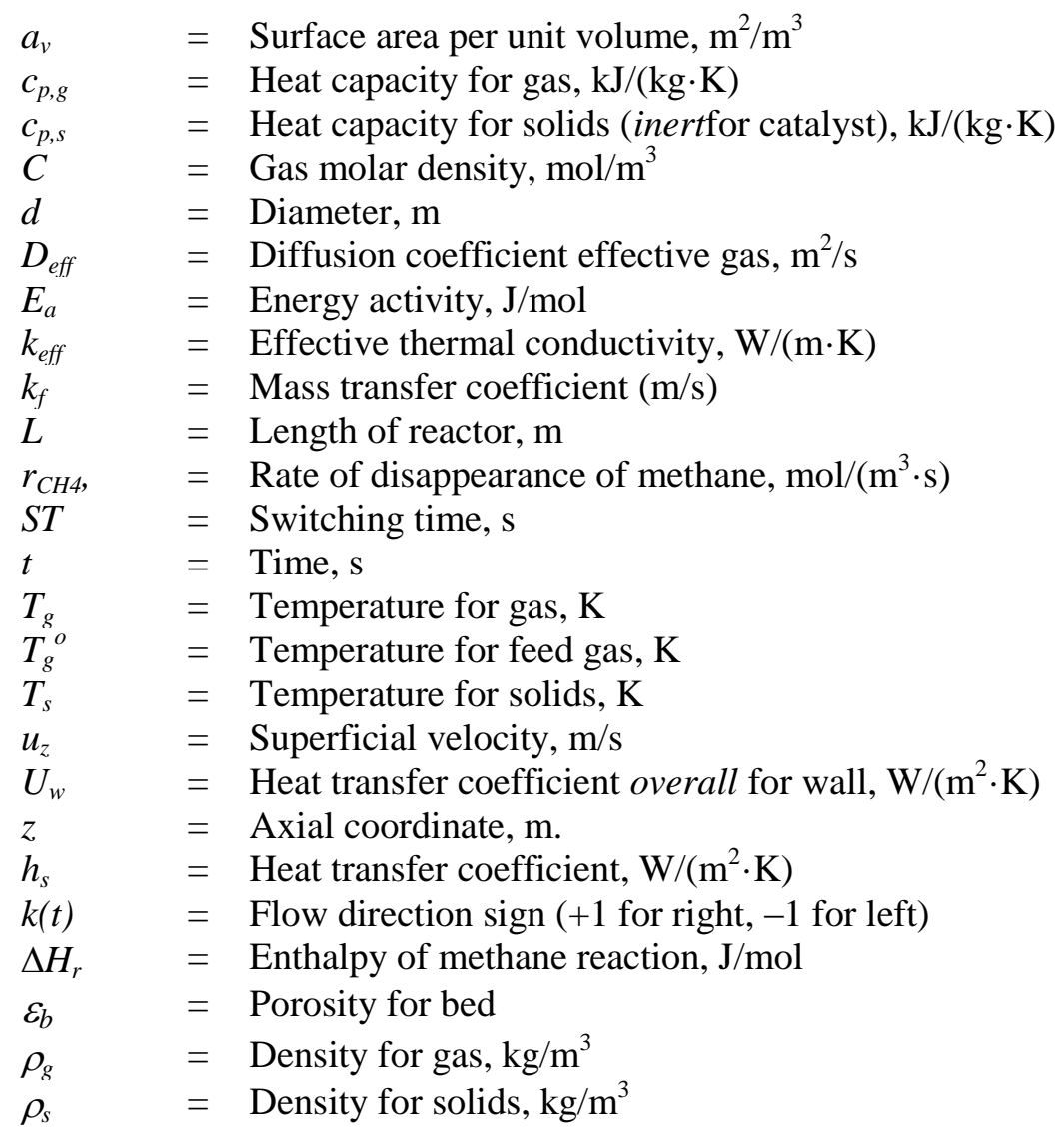

\section{References}

[1] Froment, G.F. \& Bischoff, K.B., Chemical Reactor Engineering Analysis and Design, $2^{\text {nd }}$ edition, John Wiley \& Sons, New York, 1990. 
[2] Hayes, R.E., Catalytic Solutions for Fugitive Methane Emissions in the Oil and Gas Sector, Chemical Engineering Science, 59, pp. 4073-4080, 2004.

[3] Tullilah, M.B., Alajem, E., Gal, R. \& Sheintuch, M., Flow-Rate Effects in Flow-Reversal Reactor: Experiments, Simulations and Approximations, Chemical Engineering Science, 58, pp. 1135-1146, 2003.

[4] Sheintuch, M. \& Nekhamkina, O., Comparison of Flow-Reversal, Internal-Recirculation and Loop Reactors, Chemical Engineering Science, 59, pp. 4065-4070, 2004.

[5] Cittadini, M., Vanni, M. \& Barresi, A.A., Transient Behavior and Startup of Periodic Flow Reactors for Catalytic Decontamination of Waste Gases, Chemical Engineering and Processing, 41, pp. 437-443, 2002.

[6] Hevia, M.A.G., Ordonez, S. \& Diez, F.V., Combustion of Medium Concentration $\mathrm{CH}_{4}$-Air Mixtures in Non-Stationary Reactors, Chemical Engineering Journal, 131, pp. 343-349, 2007.

[7] Matros, Yu.Sh. \& Bunimovich, G.A., Reverse Flow Operation in Fixed Bed Catalytic Reactor, Catalysis Reviews-Science and Engineering, 38(1), pp. 1-68, 1996.

[8] Budhi, Y.W., Hoebink, J.H.B.J. \& Schouten, J.C., Reverse Flow Operation with Reactor SideFeeding: Analysis, Modeling, and Simulation, Industrial and Engineering Chemistry Research, 43, pp. 6955-6963, 2004.

[9] Mears, D.E., Test for Transport Limitation in Experimental Catalytic Reactors, Industrial and Engineering Chemistry Process Design Development, 10(4), pp. 541-547, 1971.

[10] Salinger, A.G. \& Eigenberger, G., The Direct Calculation of Periodic States of the Reverse Flow Reactor - I. Methodology and Propane Combustion Results, Chemical Engineering Science, 51(21), pp. 49034913, 1996.

[11] Iordanidis, A.A., Mathematical Modeling of Catalytic Fixed Bed Reactors, Ph.D. Dissertation, University of Twente, Enschede, the Netherlands, 2002.

[12] Hevia, M.A.G., Ordonez, S.\& Diez, F.V., Effect of the Catalyst Properties on the Performance of a Reverse Flow Reactor for Methane Combustion in Lean Mixtures, Chemical Engineering Journal, 129, pp. 110, 2007.

[13] Budhi, Y.W., Jaree, A., Hoebink, J.H.B.J. \& Schouten, J.C., Simulation of Reverse Flow Operation for Manipulation of Catalyst Surface Coverage in the Selective Oxidation of Ammonia, Chemical Engineering Science, 59, pp. 4125-4135, 2004.

[14] Marín, P., Ordóñes, S. \& Díez, F.V., Combustion of Toluene-Hexane Binary Mixtures in a Reverse Flow Catalytic Reactor, Chemical Engineering Science, 63, pp. 5003-5009, 2008. 
[15] Kushwaha, A., Poiriera, H.M., Sapoundjiev, H. \& Hayes, R.E., Effect of Reactor Internal Properties on the Performance of a Flow Reversal Catalytic Reactor for Methane Combustion, Chemical Engineering Science, 59, pp. 4081-4093, 2004.

[16] Bosomiu, M., Bozga, G. \& Soare, G., Methane Combustion over a Commercial Platinum on Alumina Catalyst: Kinetics and Catalyst Deactivation, Revue Roumaine de Chimie, 53(12), pp. 1105-1115, 2008.

[17] Barresi, A.A. \& Vanni, M., Control of Catalytic Combustors with Periodical Flow Reversal, AIChE J, 48, pp. 648-652, 2002. 